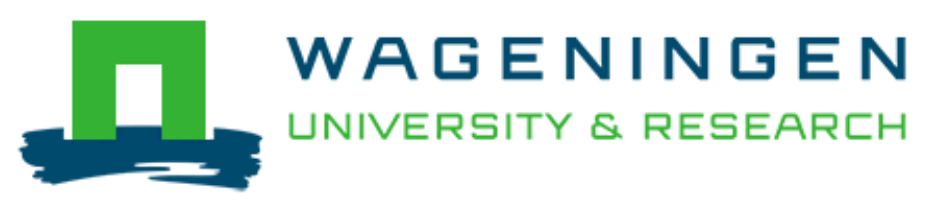

\title{
Relationships between methane production and milk fatty acid profiles in dairy cattle
}

Dijkstra, J., van Zijderveld, S. M., Apajalahti, J. A., Bannink, A., Gerrits, W. J. J., Newbold, J. R., ... Berends, H.

This is a "Post-Print" accepted manuscript, which has been published in "Animal Feed Science and Technology"

This version is distributed under a non-commercial no derivatives Creative Commons (a) (1) $\Theta \Theta$ reproduction in any medium, provided the original work is properly cited and not used for commercial purposes. Further, the restriction applies that if you remix, transform, or build upon the material, you may not distribute the modified material.

Please cite this publication as follows:

Dijkstra, J., van Zijderveld, S. M., Apajalahti, J. A., Bannink, A., Gerrits, W. J. J., Newbold, J. R., ... Berends, H. (2011). Relationships between methane production and milk fatty acid profiles in dairy cattle. Animal Feed Science and Technology, 166167, 590-595. DOI: 10.1016/j.anifeedsci.2011.04.042

You can download the published version at:

https://doi.org/10.1016/j.anifeedsci.2011.04.042 
1

2

3

4

5

6

7

8

9

10

11

12

13

14

15

16

17

18

19 20

21

22

23

24

$25 *$ Corresponding author:

26 phone: +31 317484082

27 fax: +31 317484062

28 e-mail: jan.dijkstra@wur.nl cattle

J. Dijkstra $^{a^{*}}$, S.M. van Zijderveld ${ }^{\mathrm{b}}$, J.A. Apajalahti ${ }^{\mathrm{c}}$, A. Bannink ${ }^{\mathrm{d}}$, W.J.J. Gerrits ${ }^{\mathrm{a}}$, J.R. Newbold $^{\mathrm{b}}$, H.B. Perdok ${ }^{\mathrm{b}}$, H. Berends ${ }^{\mathrm{a}}$

a Animal Nutrition Group, Wageningen University, P.O. Box 338, 6700 AH Wageningen, the Netherlands

b Provimi Research Centre, Veilingweg 23, 5334 LD Velddriel, the Netherlands ${ }^{\mathrm{c}}$ Alimetrics, Koskelontie 19B, FI-02920 Espoo, Finland

${ }^{\mathrm{d}}$ Livestock Research, Animal Sciences Group, Wageningen University and Research Centre, Lelystad, the Netherlands 


\section{Abstract}

There is a need to develop simple ways of quantifying and estimating methane production in cattle. Our aim was to evaluate the relationship between methane production and milk fatty acid (FA) profile in order to use milk FA profiles to predict methane production in dairy cattle. Data from three experiments with dairy cattle with a total of 10 dietary treatments and 50 observations were used. Dietary treatments included supplementation with calcium fumarate, diallyldisulfide, caprylic acid, capric acid, lauric acid, myristic acid, extruded linseed, linseed oil and yucca powder. Methane was measured using open-circuit indirect respiration calorimetry chambers and expressed as g/kg dry matter (DM) intake. Milk FA were analyzed by gas chromatography and individual FA expressed as a fraction of total FA. To determine relationships between milk FA profile and methane production, univariate mixed model regression techniques were applied including a random experiment effect. A multivariate model was developed using a stepwise procedure with selection of FA based on the Schwarz Bayesian Information Criterion. Dry matter intake was $17.7 \pm$ $1.83 \mathrm{~kg} /$ day, milk production was $27.0 \pm 4.64 \mathrm{~kg} /$ day, and methane production was $21.5 \pm 1.69$ g/kg DM. Milk C8:0, C10:0, C11:0, C14:0 iso, C15:0 iso, C16:0 and C17:0 anteiso were positively related $(P<0.05)$ to methane $(\mathrm{g} / \mathrm{kg} \mathrm{DM}$ intake), whereas C17:0 iso, cis-9 C17:1, cis-9 C18:1, trans-10+11 C18:1, cis-11 C18:1, cis-12 C18:1 and cis-14+trans-16 C18:1 were negatively related $(P<0.05)$ to methane. Multivariate analysis resulted in the equation: methane $(\mathrm{g} / \mathrm{kg} \mathrm{DM})=24.6 \pm 1.28+8.74 \pm 3.581 \times$ C17:0 anteiso $-1.97 \pm 0.432 \times$ trans-10+11 C18:1 $-9.09 \pm 1.444 \times$ cis-11 C18: $1+$ $5.07 \pm 1.937 \times$ cis-13 C18:1 (individual FA in $\mathrm{g} / 100 \mathrm{~g} \mathrm{FA} ; \mathrm{R}^{2}=0.73$ after correction for experiment effect). This confirms the expected positive relationship between methane and C14:0 iso and C15:0 iso in milk FA, as well as the negative relationship between methane and various trans-intermediates, particularly trans-10+11 C18:1. However, in contrast with expectations, C15:0 and C17:0 were not related to methane production. Milk FA profiles can predict methane production in dairy cattle.

This paper is part of the special issue entitled: Greenhouse Gases in Animal Agriculture - Finding a Balance between Food and Emissions, Guest Edited by T.A. McAllister, Section Guest Editors; K.A. Beauchemin, X. Hao, S. McGinn and Editor for Animal Feed Science and Technology, P.H. Robinson.

Keywords: methane, dairy cow, milk fatty acid profile 
Abbreviations: DM, dry matter; FA, fatty acid; OBCFA, odd- and branched-chain fatty acids; VFA, volatile fatty acids

\section{Introduction}

Various dietary strategies have been proposed to reduce production of methane by dairy cattle (Beauchemin et al., 2009). Accurate measurements of methane production from cattle in various dietary situations require complex and expensive techniques. Mathematical models may allow prediction of methane production from cattle without undertaking extensive experiments. However, the accuracy of empirical models to predict methane production for inventory or mitigation purposes is low (Ellis et al., 2010), and mechanistic models are complex and require inputs that are not commonly measured. Thus development of simple indicators to estimate methane production in cattle is of substantive interest.

Vlaeminck and Fievez (2005) suggested that odd- and branched-chain fatty acids (OBCFA) in milk may be used as markers of microbial activity, as OBCFA have a strong relationship with molar proportions of individual volatile fatty acids (VFA) in the rumen (Vlaeminck et al., 2006), which in turn are related to methane production (Ellis et al., 2008). In their model, Vlaeminck and Fievez (2005) reported a positive relationship of methane predicted from rumen VFA molar proportions with C15:0 iso, and a negative relationship with C15:0 content of milk fat. However, in an experiment comparing a control diet with a myristic acid supplemented diet, Odongo et al. (2007) did not find reduced C15:0 iso or increased C15:0 at lower methane production, although milk fat C14:0 iso was negatively related to methane production. Chilliard et al. (2009) evaluated effects of various dietary linseed treatments on methane production in dairy cattle and did find relationships of milk contents of C15:0 and C15:0 iso with methane, but relationships of other milk FA with methane were stronger. Although milk FA profile may be a potential indicator of methane production, actual determined relationships in vivo are limited to diets varying in type and availability of dietary FA. A wider variety of diets is required to explore the more general potential of milk FA profile as an indicator.

Our aim was to evaluate relationships between methane production and milk FA profiles in dairy cattle, and to use FA profiles in milk to predict methane production. 


\section{Material and methods}

\subsection{Data}

Data from three experiments, all designed as randomized block experiments, with a total of 50 observations from 100 cows were used. The experiments were completed in Wageningen and the Animal Care and Use Committee of Wageningen University, the Netherlands, approved the experimental protocols. In all experiments, after an adaptation period of 12 days, cows were housed in pairs in two identical, open-circuit, indirect climate respiration chambers for 6 (experiment 1) or 3 (experiments 2 and 3) days. Each pair of cows consisted of two cows on the same treatment, and consequently each observation is the mean value of a pair of cows. Diets were fed as a total mixed ration twice daily and intake was restricted to 0.95 of the amount that was consumed voluntarily by the cow consuming the least within the pair of 2 (experiment 1) or 4 (experiments 2 and 3) cows. Cows were milked twice daily. In experiment 1 (Van Zijderveld et al., 2011a) 20 lactating Holstein-Friesian dairy cows were fed a control diet that included rumen inert fat from palm oil, or a diet supplemented with calcium fumarate in which the palm oil was substituted for lauric acid, myristic acid and linseed oil. The basal diet was (DM basis) 0.29 grass silage, 0.22 maize silage, 0.02 wheat straw and 0.47 concentrate. In experiment 2 (Van Zijderveld et al., 2011b) 40 lactating Holstein-Friesian dairy cows were fed a control diet or a diet containing diallyldisulfide, yucca plant powder, or calcium fumarate. The diet was 0.26 maize silage, 0.40 grass silage and 0.34 concentrates on a DM basis. In the third experiment (Van Zijderveld et al., 2011b), 40 lactating Holstein-Friesian dairy cows were fed a control diet or diets supplemented with extruded linseed, diallyldisulfide, or a mixture of caprylic acid and capric acid. The diet contained (DM basis) 0.41 grass silage, 0.35 maize silage and 0.24 concentrates.

Methane production was determined in 9 min intervals as described by Van Knegsel et al. (2007). Milk production was recorded during the presence of the cows in the respiration chambers and a sample was obtained at each milking. The samples were pooled, weighted by production, to one sample for analyses of milk composition. Milk FA composition of the cows per chamber was calculated as the weighted average of the respective analyzed FA composition and milk fat yield. After extraction and methylation, milk FA were analyzed by gas chromatography (Van Knegsel et al. 2007) and individual FA were expressed as a fraction of total FA. Peaks were identified using external standards (S37, Supelco, Bellefonte, PA, USA; OBCFA 
131 and various trans-FA, Larodan Fine Chemicals AB, Malmö, Sweden). The analysis

132 did not allow several C18:1 isomers to be completely resolved and therefore some FA

133 are summarized together in Table 1. The milk fat and milk protein contents were 134 similar to average contents of Dutch bovine milk (4.38 and 3.48 g/100 g milk; Heck et 135 al., 2009).

\section{$136 \quad$ 2.2. Statistical analysis}

137 To determine the relationship between individual milk FA and methane 138 production, a mixed model univariate regression techniques (PROC MIXED of SAS, 139 2007) were applied which included a discrete random experiment effect and 140 individual milk FA as fixed effects. Treating the experiment effect as a random effect 141 caused the equation parameter estimates to be estimated first within study, and then 142 averaged to obtain overall estimates. Distribution of random effects was assumed to 143 be normal with an unstructured variance-covariance matrix for the intercepts and 144 slopes. In addition, a multivariate model was developed using a stepwise procedure 145 (PROC GLMSELECT of SAS, 2007) retaining the experiment effect in every step, 146 with methane production being the independent variable and stepwise selection of FA 147 based on the Schwarz Bayesian Information Criterion. Adjusted independent variable 148 values were calculated based on regression parameters of the final model to determine 149 the $\mathrm{r}_{\text {or }} \mathrm{R}^{2}$ corrected for experiment effect (St-Pierre, 2001).

\section{Results and Discussion}

152

Dry matter intake is a major determinant of methane production from cattle (e.g.,

153 Bannink et al., 2010). A higher DM intake will generally result in increased amounts 154 of organic matter fermented in the rumen with associated production of VFA and 155 gases. Indeed in the present analysis, DM intake was positively related $(P<0.001 ; \mathrm{r}=$ 156 0.84) to methane production with a slope of $23.1 \pm 2.38$ g methane/kg DM intake. To 157 evaluate dietary mitigation options, variation in the amount of methane produced per 158 unit feed is of more interest than total output of methane because it avoids 159 confounding effects of DM intake on methane production, and because DM intake is 160 known or can be estimated with reasonable accuracy in stall-fed cows. Therefore, 161 methane produced per kg of feed DM was related to individual FA concentrations in 162 milk fat, and results are in Table 2.

163 Consistent with Odongo et al. (2007) and Chilliard et al. (2009), methane 164 production was positively correlated $(P<0.05)$ with C8:0, C10:0, C11:0 and C16:0 (all 
$165 \mathrm{~g} / 100 \mathrm{~g}$ total FA). However, Johnson et al. (2002) did report reduced concentrations 166 of C10:0, C12:0, C14:0 and C16:0 in milk fat upon supplementation with cottonseed 167 and canola seed, and methane production was not affected. These FA are mainly 168 derived from de novo synthesis in the mammary gland from acetate and 3-hydroxy 169 butyrate (Bernard et al., 2008). Formation of acetate in the rumen, largely as the result 170 of fermentation of fibre (Bannink et al., 2008), results in the production of hydrogen 171 gas that is used to produce methane by methanogenic archaea. A range of dietary 172 unsaturated FA may reduce methane production (Beauchemin et al., 2009). Since 173 various unsaturated FA are also known to inhibit de novo synthesis of FA with 16 174 carbons or less, with the possible exception of C4:0 (Bernard et al., 2008), this may 175 also explain the relationship between methane and de novo synthesised FA. Indeed, of 176 FA with 16 carbons or less, only $\mathrm{C} 4: 0$ tended $(P=0.07)$ to be negatively related to 177 methane production.

178 Consistent with theoretical expectations (Vlaeminck and Fievez, 2005), and with 179 experimental data (Chilliard et al., 2009), C14:0 iso and C15:0 iso in milk fat were 180 positively related ( $P=0.02$ and 0.003 , respectively) to methane, but C17:0 iso was 181 negatively related $(P=0.02)$. Fibrolytic bacteria are enriched in C14:0 iso and C15:0 182 iso, and an increase in dietary forage to concentrate ratio, which will generally 183 increase methane production, is also associated with higher levels of C14:0 iso and 184 C15:0 iso in milk fat (Vlaeminck et al., 2006). Odongo et al. (2007) reported a 185 numerical decrease of C17:0 anteiso accompanied by a decrease of methane in the 186 myristic supplemented diet. In our study, a positive relationship $(P<0.001)$ between 187 methane and C17:0 anteiso also occurred. Cabrita et al. (2003) reported a negative 188 relationship between dietary crude protein content and C17:0 anteiso content in milk 189 fat, and a positive relationship between dietary fibre content and C17:0 anteiso. 190 Because, stoichiometrically, fermentation of protein is associated with a lower 191 methane production compared with fermentation of fibre or sugars (Bannink et al., 192 2008), such associations between dietary crude protein, fibre and milk C17:0 anteiso 193 may explain the positive relationship of this FA with methane.

194 A high propionic acid level in the rumen is associated with low methane 195 production, and propionic acid is a substrate for de novo synthesis of C15:0 and 196 C17:0. Thus Vlaeminck and Fievez (2005) expected a negative relationship between 197 these odd chain FA and methane, but Chilliard et al. (2009) reported a positive 198 correlation between these odd chain FA and methane. Odongo et al. (2007) did not 
199 find changes in C15:0 and C17:0 contents with changes in methane production. In our 200 analysis, C15:0 was not related with methane and C17:0 tended $(P=0.07)$ to be 201 positively related. However, cis-9 C17:1 was negatively related $(P<0.001)$ to 202 methane. Cis-9 C17:1 is a desaturation product of C17:0 in the mammary gland. The 203 sum of C17:0 and cis-9 C17:1 was negatively related $(P=0.03)$ to methane production 204 (results not shown). Supplementation with linseed changed mammary desaturation 205 activity, which may have caused relationships between milk FA and methane in 206 Chilliard et al. (2009) to differ from others, and in our findings.

207 Milk content of many unsaturated FA, such as cis-9 C18:1, trans-10+11 C18:1, 208 cis-11 C18:1, cis-12 C18:1 and cis-14+trans-16 C18:1, were all negatively associated 209 with methane production, which largely agrees with Chilliard et al. (2009). However, 210 In Odongo et al. (2007), supplementation with myristic acid decreased methane 211 production but trans-10 C18:1, trans-11 C18:1, and cis-11 C18:1 were not affected, 212 whilst cis-9 C18:1 and cis-12 C18:1 were lower in the supplemented diet. A number 213 of these unsaturated FA originate in the rumen, but the microorganisms and enzymes 214 responsible for their production are not yet well characterized or understood (Wallace 215 et al., 2007).

216 Supplementation with various dietary fat sources may reduce methane production 217 (Beauchemin et al., 2009) and increase formation of ruminal biohydrogenation 218 intermediates (Harfoot and Hazlewood, 1997). Fibre degradation in the rumen may 219 decrease with dietary addition of fat, and this further explains the variation in the relationships between contents of various biohydrogenation intermediates and methane production.

Multivariate analysis using a stepwise approach resulted in the equation 223 (experiment effect not presented):

$$
\begin{aligned}
\text { methane }(\mathrm{g} / \mathrm{kg} \mathrm{DM})= & 24.6 \pm 1.28+8.74 \pm 3.581 \times \mathrm{C} 17: 0 \text { anteiso }-1.97 \pm 0.432 \\
& \times \text { trans }-10+11 \mathrm{C} 18: 1-9.09 \pm 1.444 \times \text { cis- } 11 \mathrm{C} 18: 1+5.07 \pm \\
& 1.937 \times \text { cis- } 13 \mathrm{C} 18: 1
\end{aligned}
$$

227 where individual $\mathrm{FA}$ are in $\mathrm{g} / 100 \mathrm{~g}$ FA and $\mathrm{R}^{2}=0.73$ after correction for the 228 experiment effect (St-Pierre, 2001) with all parameters $P<0.02$ (see Figure 1 for 229 observed and predicted relationship and residual methane production). The $\mathrm{R}^{2}$ of this 230 equation is lower than the best equation derived by Chilliard et al. (2009). However, 231 Chilliard et al. (2009) obtained relationships using absolute methane production 232 (g/day) rather than methane produced/kg feed DM, and they only used diets that 
233 varied in supply and availability of linolenic acid, which may have increased the $\mathrm{R}^{2}$ 234 compared with our approach.

235 However our study shows high potential for milk FA to be used as an indicator of 236 methane produced $/ \mathrm{kg}$ feed consumed. The number of data $(\mathrm{n}=50)$ and studies $(\mathrm{n}=3)$

237 used in our analysis were limited and, within experiment there was no variation in 238 type, composition or proportion of dietary forage and concentrate, which may limit 239 application of our equation to other diets. For example, the high contents of trans240 10+11 C18:1 (10 g/100 g milk total FA) by feeding docosahexaenoic acid enriched 241 diets (Boeckaert et al., 2008) would likely result in predicted methane production 242 being close to zero. More data are needed to confirm relationships between milk FA 243 profile and methane production for a wide range of dietary conditions.

\section{Conclusions}

Various milk fatty acids showed moderate relationships with methane production in dairy cattle. In particular, C14:0 iso, C15:0 iso and C17:0 anteiso were positively related with methane production, and cis-9 C17:1 and various FA arising from ruminal biohydrogenation of FA were negatively related with methane production. Milk FA profile can be used to predict the formation of methane in dairy cattle, but

\section{Acknowledgements}

Data on DM intake, milk production and methane production were obtained in experiments partially funded by SenterNovem, an agency of the Dutch Ministry of 256 Economic Affairs.

\section{References}

259 Bannink, A., Smits, M.C.J., Kebreab, E., Mills, J.A.N., Ellis, J.L., Klop, A., France, J., Dijkstra, J., 2010. Simulating the effects of grassland management and grass ensiling on methane emission from lactating cows. J. Agric. Sci., Camb. 148, 5572.

Bannink, A., France, J., Lopez, S., Gerrits, W.J.J., Kebreab, E., Tamminga, S., Dijkstra, J., 2008. Modelling the implications of feeding strategy on rumen fermentation and functioning of the rumen wall. Anim. Feed Sci. Technol. 143, 326. 
Beauchemin, K.A., McAllister, T.A., McGinn, S.M., 2009. Dietary mitigation of enteric methane from cattle. CAB Reviews: Perspectives in Agriculture, Veterinary Science, Nutrition and Natural Resources, 4, No. 035.

Bernard, L., Leroux, C., Chilliard, Y., 2008. Expression and nutritional regulation of lipogenic genes in the ruminant lactating mammary gland. Adv. Exp. Med. Biol. 606, 67-108.

Boeckaert, C., Vlaeminck, B., Dijkstra, J., Issa-Zacharia, A., van Nespen, T., Van Straalen, W., Fievez, V., 2008. Effect of dietary starch or micro algae supplementation on rumen fermentation and milk fatty acid composition of dairy cows. J. Dairy Sci. 91, 4714-4727.

Cabrita, A.R.J., Fonseca, A.J.M., Dewhurst, R.J., Gomes, E., 2003. Nitrogen supplementation of corn silages. 2. Assessing rumen function using fatty acid profiles of bovine milk. J. Dairy Sci. 86, 4020-4032.

Chilliard, Y., Martin, C., Rouel, J., Doreau, M., 2009. Milk fatty acids in dairy cows fed whole crude linseed, extruded linseed, or linseed oil, and their relationship with methane output. J. Dairy Sci. 92, 5199-5211.

Ellis, J.L., Bannink, A., France, J., Kebreab, E., Dijkstra, J., 2010. Evaluation of enteric methane prediction equations for dairy cows used in whole farm models. Glob. Change Biol. 16, 3246-3256.

Ellis, J.L., Dijkstra, J., Kebreab, E., Bannink, A., Odongo, N.E., McBride, B.W., France, J., 2008. Aspects of rumen microbiology central to mechanistic modelling of methane production in cattle. J. Agric. Sci., Camb. 146, 213-233.

Harfoot G.C., Hazlewood, G.P., 1997. Lipid metabolism in the rumen, in: Hobson, P.N., C.S. Stewart (Eds.), The Rumen Microbial Ecosystem. 2nd ed. Blackie Academic \& Professional, London, UK, pp 382-426.

Heck, J.M.L., van Valenberg, H.J.F., Dijkstra, J., van Hooijdonk, A.C.M., 2009. Seasonal variation in the Dutch bovine raw milk composition. J. Dairy Sci. 92, 4745-4755.

Johnson, K.A., Kincaid, R.L., Westberg, H.H., Gaskins, C.T., Lamb, B.K., Cronrath, J.D., 2002. The effect of oilseeds in diets of lactating cows on milk production and methane emissions. J. Dairy Sci. 85, 1509-1515.

Odongo, N.E., Or-Rashid, M.M., Kebreab, E., France, J., McBride, B.W., 2007. Effect of supplementing myristic acid in dairy cow rations on ruminal methanogenesis and fatty acid profile in milk. J. Dairy Sci. 90, 1851-1858. 
SAS Institute Inc. (2007) SAS/STAT® User’s Guide, Version 9.2. Cary, NC, USA.

St-Pierre, N.R., 2001. Invited review: integrating quantitative findings from multiple studies using mixed model methodology. J. Dairy Sci. 84, 741-755.

Van Knegsel, A.T.M., Van den Brand, H., Dijkstra, J., Van Straalen, W.M., Heetkamp, M.J.W., Tamminga, S., Kemp, B., 2007. Dietary energy source in dairy cows in early lactation: energy partitioning and milk composition. J. Dairy Sci. 90, 1467-1476.

Van Zijderveld, S.M., Fonken, B.C.J., Dijkstra, J., Gerrits,W.J.J., Perdok, H.B., Fokkink, W.B., Newbold, J.R., 2011a. Effects of a combination of feed additives on methane production, diet digestibility and animal performance in lactating dairy cows. J. Dairy Sci. 94, 1445-1454.

Van Zijderveld, S.M., Dijkstra, J., Perdok, H.B., Newbold, J.R., Gerrits, W.J.J., 2011b. Dietary inclusion of diallyldisulfide, yuccapowder, calcium fumarate, an extruded linseed product, or medium-chain fatty acids does not affect methane production in lactating dairy cows. J. Dairy Sci 94, 3094-3104.

Vlaeminck, B., Fievez, V., 2005. Milk odd and branched-chain fatty acids to predict ruminal methanogenesis in dairy cows. Comm. Appl. Biol. Sci., Ghent Univ. 70, 43-47.

Vlaeminck, B., Fievez, V., Tamminga, S., Dewhurst, R.J., Van Vuuren, A.M., De Brabander, D., Demeyer, D., 2006. Milk odd- and branched-chain fatty acids in relation to the rumen fermentation pattern. J. Dairy Sci. 89, 3954-3964.

Wallace, R.J., McKain, N., Shingfield, K.J., Devillard, E., 2007. Isomers of conjugated linoleic acids are synthesized via different mechanisms in ruminal digesta and bacteria. J. Lipid Res. 48, 2247-2254. 
Table 1

327 Summary statistics of experimental data used for modelling $(n=50)$ [data from Van

328 Zijderveld et al. (2011a, 2011b].

\begin{tabular}{|c|c|c|c|c|}
\hline & Mean & SD & Minimum & Maximum \\
\hline Dry matter intake (kg/day) & 17.7 & 1.83 & 14.0 & 20.7 \\
\hline Milk production (kg/day) & 27.0 & 4.64 & 17.6 & 35.1 \\
\hline Milk fat content (g/100 g milk) & 4.36 & 0.643 & 3.23 & 6.24 \\
\hline Milk protein content (g/100 g milk) & 3.30 & 0.287 & 2.86 & 3.99 \\
\hline Methane production (g/day) & 381 & 51.7 & 279 & 456 \\
\hline Methane per kg feed (g/kg DM) & 21.5 & 1.69 & 17.3 & 25.3 \\
\hline \multicolumn{5}{|c|}{ Milk fatty acids (g/100 g total fatty acids): } \\
\hline C4:0 & 3.13 & 0.320 & 2.45 & 3.62 \\
\hline C6:0 & 2.09 & 0.241 & 1.42 & 2.44 \\
\hline C8:0 & 1.24 & 0.170 & 0.85 & 1.51 \\
\hline C10:0 & 2.83 & 0.502 & 1.86 & 3.75 \\
\hline C11:0 & 0.308 & 0.0570 & 0.181 & 0.414 \\
\hline C12:0 & 3.29 & 0.560 & 2.07 & 4.27 \\
\hline C13:0 & 0.123 & 0.0223 & 0.101 & 0.181 \\
\hline C14:0 & 11.87 & 2.131 & 8.60 & 18.24 \\
\hline $\mathrm{C} 14: 0$ iso & 0.153 & 0.0334 & 0.093 & 0.220 \\
\hline cis-9 C14:1 & 0.963 & 0.1967 & 0.566 & 1.55 \\
\hline C15:0 & 0.970 & 0.1482 & 0.715 & 1.270 \\
\hline $\mathrm{C} 15: 0$ iso & 0.245 & 0.0509 & 0.159 & 0.458 \\
\hline $\mathrm{C} 15: 0$ anteiso & 0.443 & 0.0615 & 0.328 & 0.573 \\
\hline C16:0 & 31.30 & 4.338 & 21.41 & 38.46 \\
\hline cis-9 C16:1 & 1.85 & 0.299 & 1.26 & 2.56 \\
\hline C17:0 & 0.584 & 0.1094 & 0.383 & 0.774 \\
\hline $\mathrm{C} 17: 0$ iso & 0.203 & 0.0755 & 0.113 & 0.374 \\
\hline C17:0 anteiso & 0.227 & 0.0453 & 0.102 & 0.303 \\
\hline cis-9 C17:1 & 0.228 & 0.0534 & 0.121 & 0.385 \\
\hline C18:0 & 10.16 & 1.377 & 8.11 & 14.84 \\
\hline trans $-6+7+8+9$ C18:1 & 0.359 & 0.0722 & 0.249 & 0.543 \\
\hline trans-10+11 C18:1 & 1.10 & 0.411 & 0.506 & 2.32 \\
\hline trans-12 C18:1 & 0.305 & 0.1660 & 0.146 & 0.856 \\
\hline trans-13+14 C18:1 & 1.13 & 0.554 & 0.368 & 2.45 \\
\hline cis-9 C18:1 & 18.44 & 2.158 & 14.78 & 24.21 \\
\hline cis-11 C18:1 & 0.477 & 0.1029 & 0.304 & 0.756 \\
\hline cis-12 C18:1 & 0.237 & 0.1124 & 0.136 & 0.653 \\
\hline cis-13 C18:1 & 0.285 & 0.1181 & 0.110 & 0.651 \\
\hline cis-14+trans-16 C18:1 & 0.244 & 0.2104 & 0.104 & 0.903 \\
\hline cis-9,12 C18:2 & 1.30 & 0.244 & 0.569 & 1.82 \\
\hline cis-9, trans-11 C18:2 & 0.354 & 0.0938 & 0.175 & 0.627 \\
\hline trans-11, cis-15 C18:2 & 0.228 & 0.1798 & 0.100 & 0.771 \\
\hline cis-9,12,15 C18:3 & 0.547 & 0.1566 & 0.365 & 1.023 \\
\hline $\mathrm{C} 20: 0$ & 0.129 & 0.0190 & 0.101 & 0.173 \\
\hline
\end{tabular}


331 Table 2

332 Linear regression between methane production ( $\mathrm{g} / \mathrm{kg}$ feed $\mathrm{DM})$ and milk fatty acid

333 concentration (g/100 g total fatty acids) with experiment included as random effect.

\begin{tabular}{|c|c|c|c|c|c|c|}
\hline & Intercept & SE & Slope & $\mathrm{SE}$ & Slope $P$ & $\mathrm{r}$ \\
\hline C4:0 & 25.8 & 2.40 & -1.40 & 0.759 & 0.07 & -0.27 \\
\hline C6:0 & 18.7 & 2.18 & 1.31 & 1.039 & 0.21 & 0.19 \\
\hline C8:0 & 17.5 & 1.71 & 3.17 & 1.361 & 0.02 & 0.32 \\
\hline C10:0 & 18.6 & 1.33 & 1.02 & 0.463 & 0.03 & 0.30 \\
\hline C11:0 & 17.6 & 1.21 & 12.5 & 3.88 & 0.002 & 0.42 \\
\hline $\mathrm{C} 12: 0$ & 19.4 & 1.42 & 0.641 & 0.4255 & 0.14 & 0.21 \\
\hline C13:0 & 22.3 & 1.78 & -5.92 & 13.902 & 0.67 & -0.10 \\
\hline C14:0 & 23.2 & 1.43 & -0.151 & 0.1158 & 0.20 & -0.20 \\
\hline $\mathrm{C} 14: 0$ iso & 18.7 & 1.26 & 19.5 & 8.04 & 0.02 & 0.37 \\
\hline cis-9 C14:1 & 22.0 & 1.23 & -0.593 & 1.2279 & 0.63 & -0.07 \\
\hline C15:0 & 19.3 & 1.58 & 2.23 & 1.613 & 0.17 & 0.20 \\
\hline $\mathrm{C} 15: 0$ iso & 18.1 & 1.09 & 13.8 & 4.36 & 0.003 & 0.42 \\
\hline C15:0 anteiso & 21.7 & 1.99 & -0.676 & 4.43 & 0.88 & -0.03 \\
\hline C16:0 & 17.4 & 1.68 & 0.130 & 0.0531 & 0.02 & 0.34 \\
\hline cis-9 C16:1 & 21.0 & 1.53 & 0.232 & 0.8110 & 0.78 & 0.04 \\
\hline C17:0 & 19.1 & 1.28 & 4.04 & 2.151 & 0.07 & 0.26 \\
\hline $\mathrm{C} 17: 0$ iso & 23.1 & 0.80 & -8.18 & 3.494 & 0.02 & -0.37 \\
\hline C17:0 anteiso & 17.5 & 1.10 & 17.5 & 4.78 & $<0.001$ & 0.47 \\
\hline cis-9 C17:1 & 25.1 & 1.20 & -17.5 & 4.41 & $<0.001$ & -0.55 \\
\hline C18:0 & 21.5 & 1.82 & -0.010 & 0.1759 & 0.96 & -0.01 \\
\hline trans-6+7+8+9 C18:1 & 23.5 & 1.20 & -5.74 & 3.274 & 0.09 & -0.25 \\
\hline trans-10+11 C18:1 & 23.5 & 0.64 & -1.86 & 0.537 & 0.001 & -0.46 \\
\hline trans-12 C18:1 & 22.2 & 0.50 & -2.58 & 1.425 & 0.08 & -0.25 \\
\hline trans-13+14 C18:1 & 21.9 & 0.67 & -0.451 & 0.4805 & 0.35 & -0.15 \\
\hline cis-9 C18:1 & 26.2 & 2.08 & -0.257 & 0.1120 & 0.03 & -0.33 \\
\hline cis-11 C18:1 & 26.0 & 1.09 & -9.80 & 1.957 & $<0.001$ & -0.61 \\
\hline cis-12 C18:1 & 22.7 & 0.55 & -5.04 & 2.081 & 0.02 & -0.34 \\
\hline cis-13 C18:1 & 20.2 & 0.70 & 4.36 & 2.247 & 0.06 & 0.31 \\
\hline cis-14+trans-16 C18:1 & 22.1 & 0.42 & -2.57 & 1.207 & 0.04 & -0.33 \\
\hline cis-9,12 C18:2 & 24.3 & 1.84 & -2.20 & 1.332 & 0.11 & -0.32 \\
\hline cis-9, trans-11 C18:2 & 23.2 & 0.93 & -5.02 & 2.509 & 0.05 & -0.28 \\
\hline trans-11, cis-15 C18:2 & 22.0 & 0.44 & -2.94 & 1.524 & 0.06 & -0.29 \\
\hline cis-9,12,15 C18:3 & 21.3 & 0.92 & 0.269 & 1.5774 & 0.87 & 0.03 \\
\hline C20:0 & 22.0 & 2.15 & -6.36 & 16.37 & 0.70 & -0.08 \\
\hline
\end{tabular}


336 Figure 1. Observed and predicted methane production, and residuals (i.e., observed -

337 predicted) methane production, from the multivariate analysis including experiment as a

338 discrete class variable. Predicted methane $(\mathrm{g} / \mathrm{kg} \mathrm{DM})=24.6+8.74 \times \mathrm{C} 17: 0$ anteiso $-1.97 \times$

339 trans-10+11 C18:1 - 9.09 × cis-11 C18:1 + 5.07 × cis-13 C18:1 (individual FA in g/100 g of

340 total FA; $\mathrm{R}^{2}=0.73$ after correction for experiment effect (St-Pierre, 2001) with experiment

341 effect not shown). $\Delta$, experiment $1 ; \circ$, experiment $2 ; \diamond$, experiment 3 . The line of unit slope

342 (dotted line) represents the line of equivalence.

343

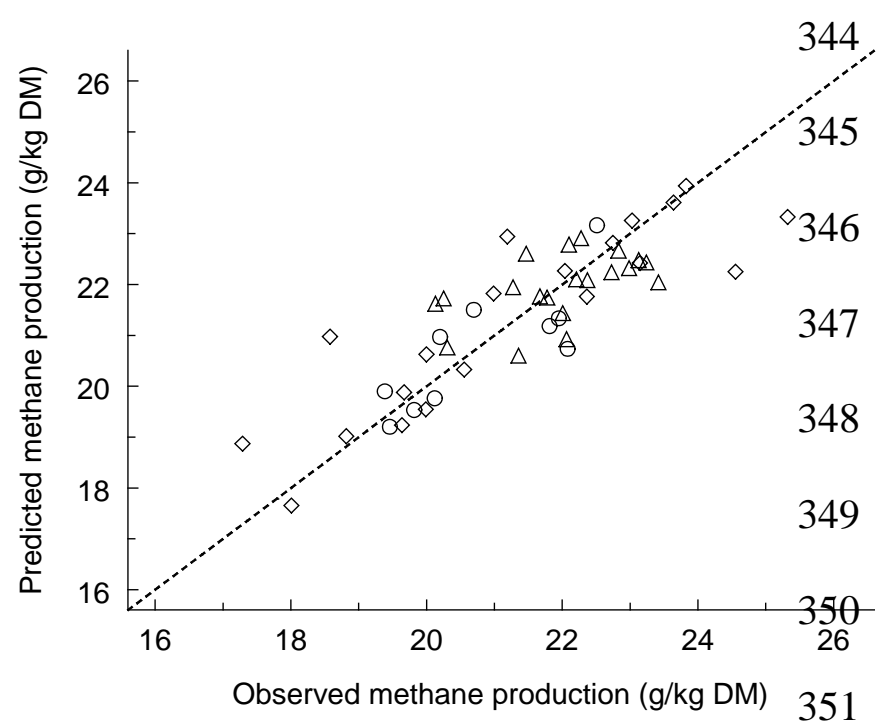

352

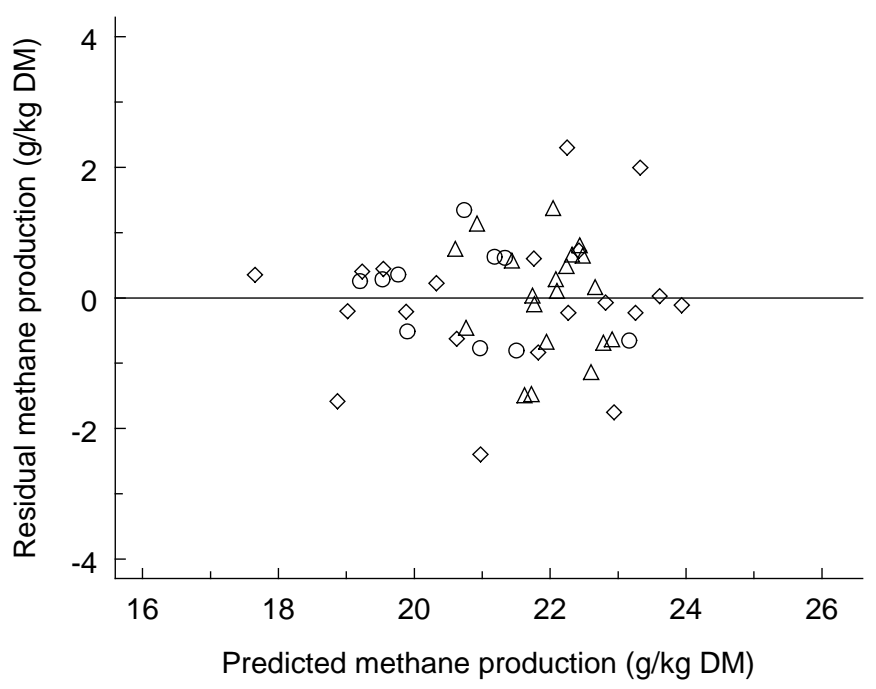


